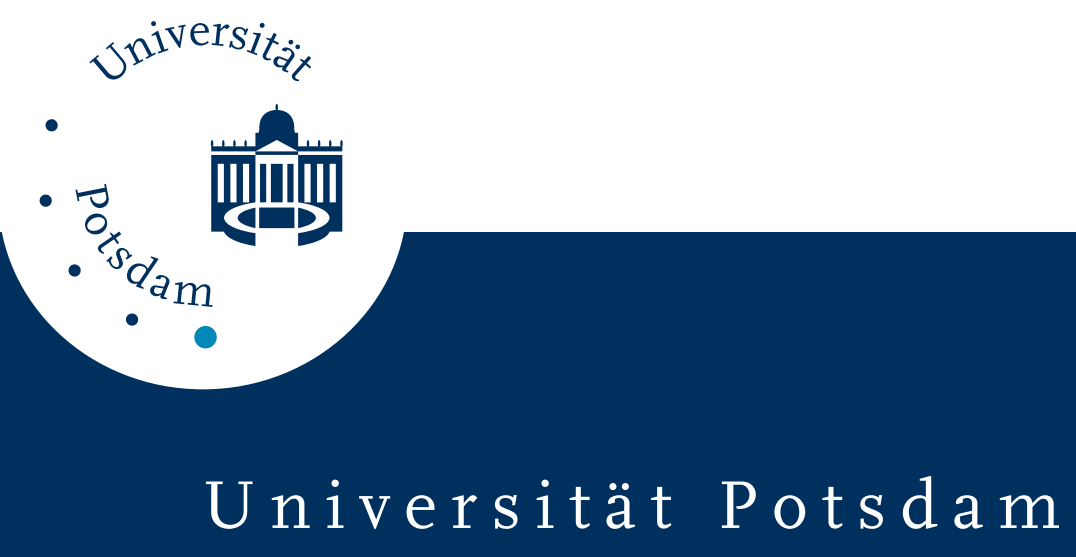

Bubeck, Christoph ; Laschewsky, André ; Lupo, Donald ; Neher, Dieter ; Ottenbreit, Petra ; Paulus, Wolfgang ; Prass, Werner ; Ringsdorf, Helmut ; Wegner, Gerhard

\title{
Amphiphilic dyes for nonlinear optics: Dependence of second harmonic generation on functional group substitution
}

first published in:

Advanced Materials, 3 (1991) S. 54-58, ISSN 0935-9648;

DOI 10.1002/adma.19910030111

Postprint published at the Institutional Repository of Potsdam University:

In: Postprints der Universität Potsdam

Mathematisch-Naturwissenschaftliche Reihe ; 82

http://opus.kobv.de/ubp/volltexte/2008/1720/

http://nbn-resolving.de/urn:nbn:de:kobv:517-opus-17201

Postprints der Universität Potsdam

Mathematisch-Naturwissenschaftliche Reihe ; 82 
crograph reveals that the surface is not at all atomically flat on a micrometer scale, but instead exhibits fairly large holes (Fig. 4). The STM images clearly show both atomically flat terraces of up to $100 \mathrm{~nm}$ in diameter coexisting with ridges and holes, $10 \mathrm{~nm}$ or more in depth (Figs. $5 \mathrm{a}, \mathrm{b}$ ).
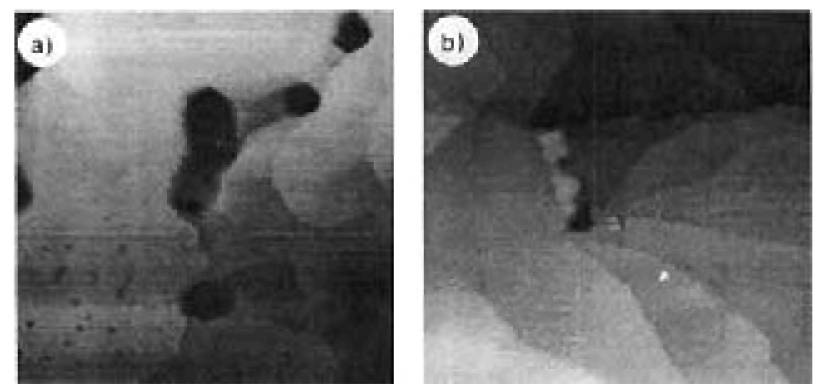

Fig. 5. STM images of $200 \mathrm{~nm}$ thick metal films evaporated at elevated substrate temperatures. Image sizes are $250 \mathrm{~nm} \times 250 \mathrm{~nm}$ and the brightness is proportional to the height, a) Au/mica, $T_{2}=400^{\circ} \mathrm{C}$. b) Ag/mica, $T_{n}=275^{\circ} \mathrm{C}$.

The observed surface structure reflects the three-stage growth mechanism of nucleation, island growth, and coalescence. At lower substrate temperatures, grains with rounded surfaces are observed, while at higher temperatures the surfaces of the individual grains are flattened. Unfortunately however, the defects at grain boundaries, such as dislocations and stacking faults arising from a slight misfit and misalignment of the nuclei, are not completely healed out duting the coalescence. Also, twinning boundaries, resulting from two different grain orientations of the mica (001) surface, are well known for foc metal films on mica! [13]

To conclude, the investigation of the surface reactions of HOPG demonstrates that it is possible to chemically attitck not only the edges of the graphite plane but also the basal plane itself. This has been achieved in a very controlled way using the STM tip. While the localization of the reaction to a few square nanometers may be of interest for information storage purposes, it also appears possible that a sitmilarly well-controlled reaction on a more macroscopic scale may promote the adhesion of organic layers to HOPG. Gold and silver films evaporated onto glass or mica appear flat under more conventional microscopes. On mica they can be epitactically ordered. However, the STM reveals a considerable roughness in all cases, which suggests that it is difficult to form a defect-free organic monolayer in direct contact with such a substrate over areas of $1 \mu \mathrm{m}$ in diameter or more. This may explain the difficulty experienced in producing a single LB monolayer as insulator between evaporated gold and silver electrodes. It may also contribute to the relatively poor order of the first fatty-acid salt monolayer on these substrates. It should be noted that the influence of the surface roughness may be smaller for polymeric liquid crystalline monolayers. Indeed, their order can be very similar for a mono- and a multilayer. ${ }^{[a]}$ Nevertheless, it still appears necessary to examine other possible conducting substrates for ultrathin organic films, including bulk materials and metallic glasses. Clearly, STM, in combination with SEM and LEED, has proved to be a unique method for determining the surface structure of conducting substrates on the nanometer scale.

Received: June 1, 1990

[1] Y. Kuk, P. J. Silverman, Rev. Sci. Instrum. 60 (1989) 165

[2] H. Fuchs, Phys. Bh. 45 (1989) 105.

[3] J. P. Rabe, Adr. Mater, 1989, 13 and 299; Angew. Chum. Int Ed. Engl Adu. Mater. 28 (1989) 117 and 1127; Angew. Chem. Adu. Mater. 10t (1989) 117 and 115.3 .

[4] J. P. Rabe, M. Sano. D. Batchelder, A. A. Katatchev, J. Microsc. (Oxford) 152 (1988) 573 .

[5] H. Fuchs, Phys. Scripta 38 (1988) 264. H. Fuch1s, W. Eustachi, R. Seifert, Scanning 11 (1989) 139.

[6] J. P. Rabe, S. Buchholz, A. M. Ritcey, J. Vac. Sci. A 8 (1990) 679.

[7] T. R, Albrecht, M. M. Dovek, M. D. Kirk, C.A. Lang, C. F. Quate, D. T. E. Smith, Appl. Phys. Lett. 55 (1989) 1727

[8] A. A. Gewirth, A. J, Bard, J. Phys. Chem. 92 (1988) 5563.

[9] 1. O. Besenhard. J. Jaknb, U, Krebber, P. Möler, R. F. Sauter, A. Kurtze, N. Kanani, H. Meyar, I. K. H. Hörber. A. D Jannakoudakis, Z Naturforsich, $44 b$ (1989) 729 .

[10] H. Ohsawa, T. Tukuhushi, T. Kinoshita, Y. Enta, H. Ishii, T. Sagawa, Solid State Commun. 61 (1987) 347

[11] B. Reihl, I K. Gimzewski, J. M. Nicholls, E. Tosatti, Phys. Rev. $B 33$ (1986) 5770, H. Fuchs, E. Tosacti, Europhys. Lett. 3 (1987) 745.

[12] K. Reichelt. H. O. Lukz, J. Crysi. Growth $r(0)(1971) 103$.

[13] J. W. Watthews, Phil. Mag. 7 (1962) 915.

\section{Amphiphilic Dyes for Nonlinear Optics: Dependence of Second Harmonic Generation on Functional Group Substitution **}

\author{
By Christoph Bubeck, André Laschewsky, Donald Lupo,* \\ Dieter Neher, Petra Oitenbreit, Wolfgang Paulus, \\ Werner Prass, Helmut Ringsdorf, and Gerhard Wegner
}

The high degree of order in Langmuir-Blodgett (LB) films of dyes has led to considerable interest in their second order nonlinear optical properties. ${ }^{[1-10]}$ The LB method offers the opportunity to orient chromophores which would normally tend to crystallize centrosymmetrically, while providing a degree of orientation practically impossible to achieve by

[*] Dr, D. Lupo, P, Ottenbreit, Dr. W. Prass

Hoenst $A G$

P.O. Box 800320, D-3230 Frankfurt 80 (FRG)

Dr. C. Bubeck, Dr. D. Neher, Prof. G. Wegner

Max Planck Institute for Polymer Research

P.O. Box 3148, D-6500 Mainz (FRG)

Dr. A. Laschewsky, W. Paulus, Prof. H. Ringsdorf

Institute of Urganic Chemistry, Unjversity of Mainz

J.-J.-Becher-Weg 22, D-6500 Mainz (FRG)

$\left[{ }^{* *}\right]$ The authors wish to thank $U$. Shanemonn for helpfil discussions, $P$. Jeckeln. II. Issle and B. Merzed for technical assistance and T. Leslie of Hoeshst Celanese Corporation for suggesting the synthesis of the thioethers and hydroxyphenylhydrazones. This work was supported by the Bundestoinisteriatm för Forschang und Technologie Grant No. 03114008 
poling in polymer matrices in an electric field. Correspondingly, the highest values of the second order susceptibility $\chi^{(2)}(-2 \omega ; \omega, \omega)$ reported in the literature to date have been measured in LB monolayers. ${ }^{(4-6)}$ Because $\chi^{(2)}$ depends on the ability to form stable, highly ordercd films as well as on the molecular nonlinearity, the effect of different functional group substitutions can be more complicated than predicted by charge-transfer models.

In this communication we report the synthesis of derivatives of the amphiphilic phenylhydrazone and styrylpyridinium compounds reported by Lupoet al., ${ }^{[3]}$ characterization of their nonlinear optical properties, and investigation of the chromophore orientation in deposited monolayers via optical second harmonic generation (SHG). A particularly interesting result is that the thioether group is found by comparison with ether groups to increase $\chi^{(2)}$ significantly without shifting the absorption significantly closer into resonance.

The synthetic routes to the dyes investigated in this paper are summarized in Figure 1. Aromatic aldehydes served as intermediates for all compounds; the phenylhydrazones were obtained by condensation with nitrophenylhydrazones and the styrylpyridinium compounds by an aldol-condensation reaction with methylpyridinium precursors. The alkylthiobenzaldehydes were prepared by rcaction of the corresponding thiol with $p$-fluorobenzaldehyde, the aminobenzaldehydes by reaction of substituted anilines with dimethylformamide, ${ }^{[5]}$ and the 2-hydroxy-2-alkoxybenzaldehyde from the corresponding n-bromoalkane and 2,4-dihydroxybenzaldehyde. With the exception of the triply substituted $\mathrm{C}_{12}$-ether compounds the ether precursors were prepared by reaction of the corresponding alkyl bromides with hydroxybenzaldehydes.
All compounds were characterized by measurement of surface-pressure area isotherms in monolayers on a pure (Millipore or Seralpur) water subphase using a Lauda Langmuir lilm balance and the optimum conditions for deposition determined. Monolayers were deposited onto clean (hydrophilic) glass slides on the upstroke under the conditions sunmarized in Table 1.

Absorption spectra of monolayers were recorded on a Perkin-Elmer Lambda 9 spectrophotometer fitted with Glan-Thomson polarizing prisms. The substrate was mounted at $45^{\circ}$ to the light path and the absorption was measured for s- and p-polarized light. Within certain assumptions about chromophore orientation (see below) it is possible to detine from the polarization dependence of the spectra an effective average tilt of the chromphore from the substrate normal according to the model of Orrit et. al. ${ }^{[11]}$ The tilt was only estimated for monolayers of compounds 6 , 7 and $11-14$ and was found to range from about $50^{\circ}-70^{\circ}$ from the normal with, however, a large uncertainty due to the relatively low signal. The signal-to-noise ratio from the frequency doubling measurements was much larger; this is one advantage of the use of nonlineur-optical methods for the characterization of monolayers.

Second order susceptibilities for second harmonic generation $\chi^{(2)}(-2 \omega ; \omega, \omega)$ were determined using the apparatus shown in Figure 2. A passive-active mode-locked Nd: YAG laser (Quantel YG501) produced $35 \mathrm{ps}$ pulses at $\lambda=$ $1064 \mathrm{~mm}$ and energies up to $0.4 \mathrm{~mJ} / \mathrm{pulsc}$ at a rate of $10 \mathrm{~Hz}$. The beam was split into a sample and a reference channel to correct for laser energy fluctuations. As reference, a fine powder of 2-methyl-4-ritroaniline (MNA) was used. The monolayer sample was placed on a rotation stage with rota-

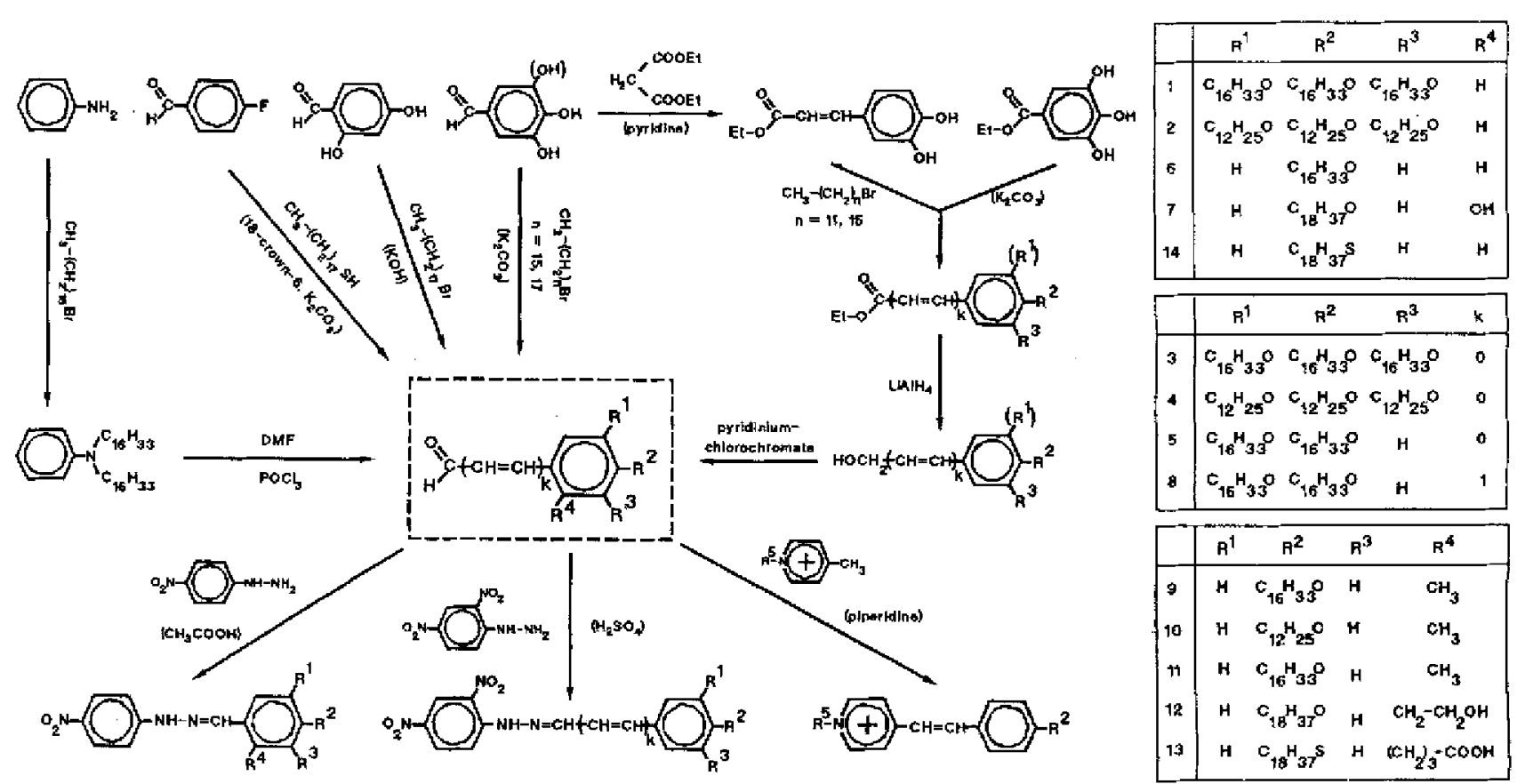

Fìg. 1. Synthesis scheme for preparation of amphiphilic dyes. 
Table 1. Deposition conditions for amphiphilie dyes.

Compound $\quad T \quad r \quad r \quad r \quad A$

$\left[\mathrm{Cl}\left[\mathrm{mN} \mathrm{m} \mathrm{m}^{-1}\right]\left[\mathrm{cmmin}^{-1}\right]\left[\mathrm{nm}^{2}\right]\right.$

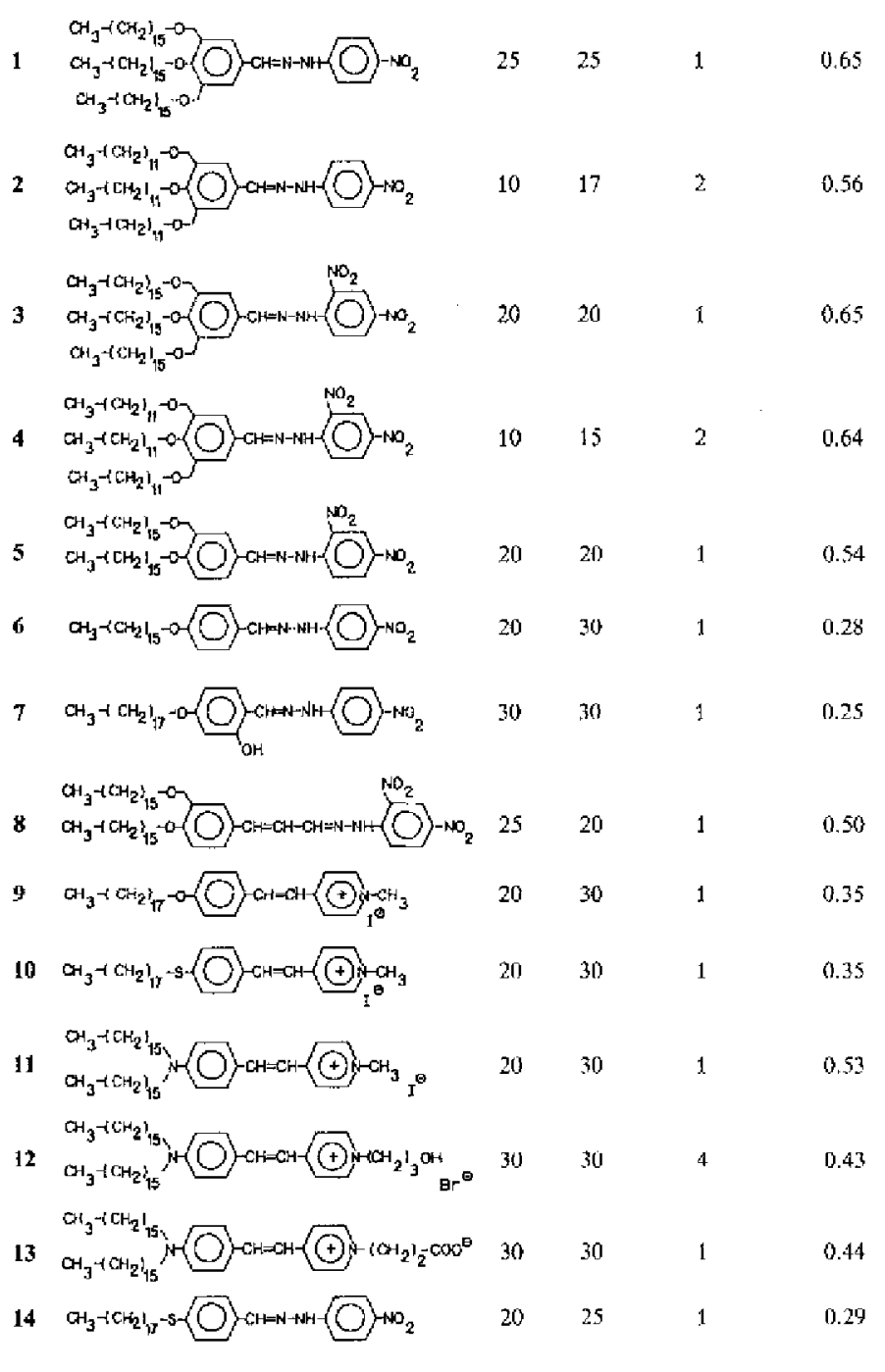

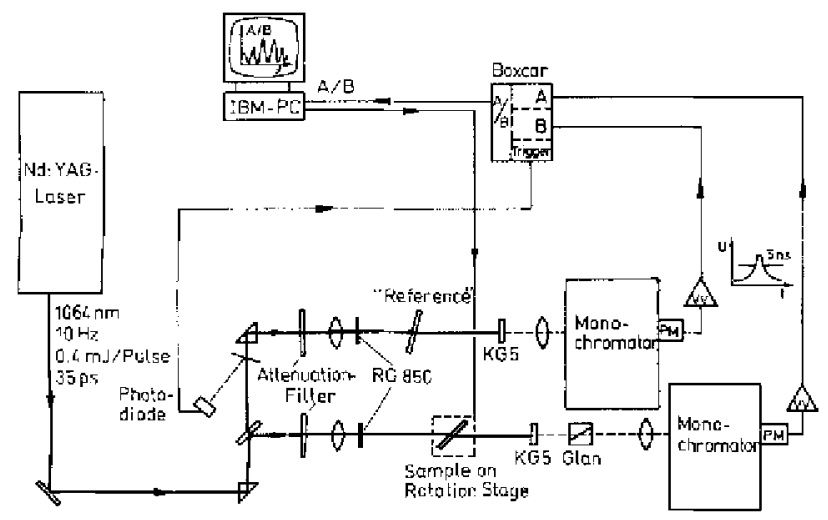

Fig. 2. Experimental apparatus for meisurement of second harmonic generation it $L B$ fitits tion axis perpendicular to the optical table. In both channels the second harmonic at $532 \mathrm{~nm}$ was selected by a monochromator, derected by a photomultiplier, amplified and processed by a Stanford boxcar gated integrator. The averaged ratio of sample to reference hamonic intensity was recorded as a function of incidence angle and stored on a personal computer, which also controlled the rolation stage. Neutral density filters were placed before and after the sample to prevent photomultiplier damage and saturation. Both fundamental and harmonic polarization could also be varied; however in this paper we restrict ourselves to experiments in which both the fundamental and harmonic beams are p-polarized. A typical result for a monolayer is shown in Figure 3. Absolute intensities were calibrated by comparison with the signal from a $3 \mathrm{~mm}$ thick Y-cut quartz plate.

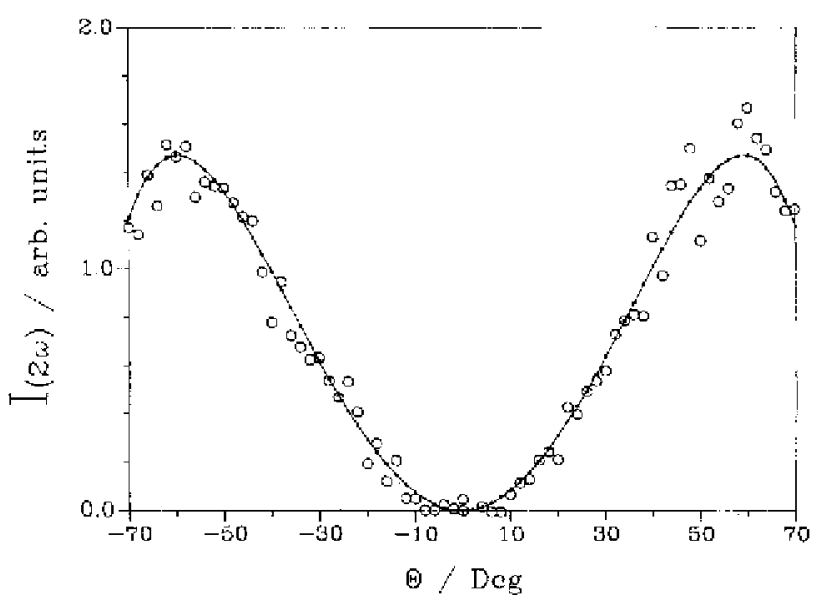

Fig. 3. lixperimental second harmonic intensity (circles) and best fit theorctical curve (solid line) as function of incidence angle for compouth 10

Nurnerous formalisms have been proposed to evaluate second harmonic generation data from monolayers $^{[5,6,12-15]}$ and the assumptions that are used can strongly affect the values of $\chi^{(2)}$ and orientations obtained. Here, we have used a simple model based on the formalism of Sipe ${ }^{[14]}$ and described in more detail by Neher ${ }^{[15]}$ Briefly, one treats the linear optical properties of the multilayer (air-monolayer-substrate) system according to the established procedures of thin film optics, ${ }^{[16]}$ and the induced nonlinear polarization $\vec{P}_{\mathrm{NL}}(2 \omega)$ as an infinitely thin sheet imbedded within the monolayer and parallel to the surface at distance $a$ from the air/film interface (Fig. 4) from which the second harmonic is radiated forwards and backwards and subsequently reflected and transmitted at the interfaces (Eq. 1)

$\vec{P}_{\mathrm{NL}}(2 \omega)=\vec{P}_{\varsigma} \delta(a)=\chi_{\mathrm{s}}^{(2)} ; \vec{E}(\omega) \vec{E}(\omega) \delta(a)$

Here $\vec{E}(\omega)$ is the sum of the forward and backward propagating waves in the film. The total amount of second harmonic transmitted into the substrate $\left(n_{2}\right)$ and reflected back 


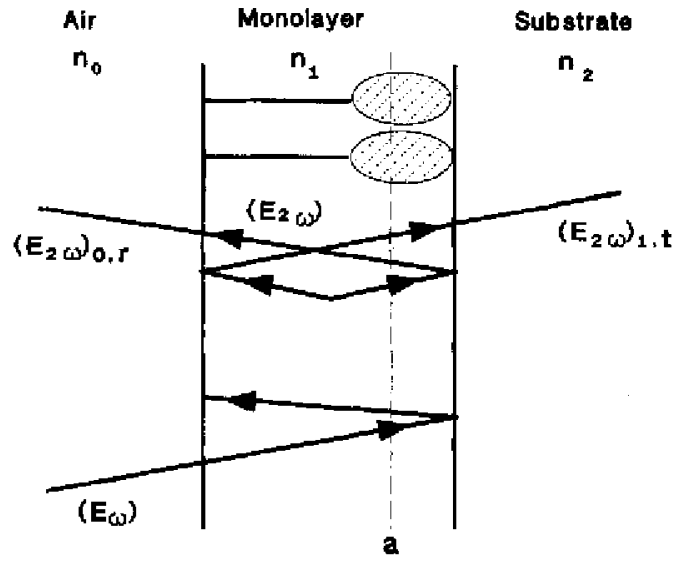

Fig. 4. Schematic representation of the model used for dala evaluation. The nonlisear polarization is considered to be locatized at a imbecded in the monoJayer.

into the air $\left(n_{0}=1\right)$ are determined using again the equations of thin film optics.

The sccond hatmonic intensity observed with given fundamental and harmonic polarizations for a particular incidence angle depends on the individual tensor components of $\chi^{\{2 \mid}$ and the projection factors from sample to laboratory coordinates. A common assumption for organic materials is that the molecular hyperpolarizability $\beta$ is dominated by the component along the chromphore axis, i.e. that $\beta=\beta_{z 2 z}$. Although this assumption may be questionable for an exact evaluation of data, it offers a convenient simplification of the data analysis for comparison of many different compounds. Furthermore, it is assumed that the molecules are symmetrically distributed about the substrate normal with a narrow distribution in the tilt angle $\varphi$. Although the assumption of a symmetric azimuthal distribution does not apply to all film systems, absorption spectra with polarized light indicate a symmetric distribution for monolayers reported here, as does the observation that $\mathrm{p}$ - or s-polarized fundamentals produced almost no s-polarized harmonic. Under these assumptions there are only two independent components of $x^{(2)}$ (Eqs. 2, 3).

$$
\chi_{\mathrm{zxz}}^{(2)}=N f^{2}(\omega) f(2 \omega) \beta_{\mathrm{zxz}}\left\langle\cos ^{3} \varphi\right\rangle
$$

$\gamma_{z x x}^{(2)}=\chi_{x x x}^{(2)}=\chi_{x y y}^{(2)}=\chi_{y x y}^{(2)}=1 / 2 N f^{2}(\omega) f(2 \omega) \beta_{z z z}\left\langle\sin ^{2} \varphi \cos \varphi\right\rangle$

$N$ is the molecular clensity, $f(\omega)$ and $f(201)$ are the local field correction factors for fundamental and harmonic, and the brackets indicate averaging over the angle $\varphi$. Under the assumption of a narrow distribution the brackets are put around the angle only. One has thus for p-polarized fundamental and harmonic and light propagating at angle $\theta$ from the normal the following dependence of the SHG intensity on incidence angle (Eq. 4).

$$
\begin{aligned}
I_{2 \omega}- & \left(x_{z z z}^{(2)} \cdot \sin \theta_{2 \omega} \cdot \sin ^{2} \theta_{\omega}+\chi_{z x x}^{(2)}\right. \\
& \left.\cdot\left(\sin \theta_{2 \omega} \cos ^{2} \theta_{\omega}+2 \cos \theta_{2 \omega} \sin \theta_{\omega} \cos \theta_{w}\right)\right) \cdot I_{\mathrm{w}}^{2}
\end{aligned}
$$

Figure 3 shows the experimental curve and the calculated best fit for compound $\mathbf{1 0}$ using the model described above and nonlinear least-squares fit routine. The values of $y^{(2)}, \beta$ and $\langle\varphi\rangle$ obtained, and the maximum intensilies compared to the maximum (at about $10^{\circ}$ ) from the quartz reference are listed in Table 2.

Tuble 2. Absorption wavelength, $x^{(2)}$ values. effective hyperpolarizabilities $p$ average effective tall angle and intensilies of second harmonjc maximat normalired against the firsl maximum from a 3 mu thick gluartz crystal. The atsterisk denotes measurements performed on substrates coated on bolh sides with a

\begin{tabular}{|c|c|c|c|c|c|c|}
\hline Cpd. & & $\begin{array}{l}\gamma_{z x x}^{(2)} \\
{\left[\mathrm{pmin}^{-1}\right]}\end{array}$ & 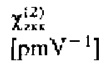 & $\begin{array}{l}I / I_{6} \\
{\left[\times 10^{-3}\right]}\end{array}$ & $\begin{array}{l}\beta \\
{\left[10^{-30} \mathrm{esu}\right]}\end{array}$ & $\begin{array}{l}\langle\phi\rangle \\
{\left[{ }^{\prime}\right]}\end{array}$ \\
\hline 1 & 430 & 15 & 6.6 & $0.66^{*}$ & 44 & 43 \\
\hline 2 & 437 & 4.0 & 4.0 & $0.15 *$ & 21 & 55 \\
\hline 3 & 407 & 16 & 10 & $1.5^{*}$ & 64 & 48 \\
\hline 4 & 407 & 2.3 & 2.5 & $0.07 *$ & 13 & 56 \\
\hline 5 & 437 & 14 & 15 & $2.6^{*}$ & 60 & 56 \\
\hline 6 & 420 & 30 & 21 & 1.7 & 57 & 50 \\
\hline 7 & 420 & 43 & 28 & 2.2 & 66 & 49 \\
\hline 8 & 417 & 25 & 14 & 2.8 & 62 & 47 \\
\hline 9 & 360 & 36 & 8.4 & 0.32 & 42 & 35 \\
\hline 10 & 380 & 76 & 9 & 0.7 & 65 & 26 \\
\hline 11 & 47.5 & 146 & 63 & 9.2 & 304 & 43 \\
\hline 12 & 475 & 146 & 36 & 4.1 & 273 & 35 \\
\hline 13 & 475 & 129 & 39 & 4.8 & 197 & 38 \\
\hline 14 & 405 & 63 & 24 & 20 & 81 & 41 \\
\hline
\end{tabular}
monolayer: for the other moasurements the monolayer was on the side facing the laser.

Comparison of the $\chi^{(2)}$ and effective $\beta$ (i.e. including possible effects of poor ordering) values of compound 6 with those of 1 and 2 confirms the common expectation that additional substitution meta to the bridge group tends to decrease molecular nonlinearity while or tho or para substitution enhances $\beta$ due to the possibility of mesomeric structures. ${ }^{[17]}$ One could have expected the additional alkyl chuins to improve the order in the film by causing tighter packing, counteracting somewhat the decrease in $\beta_{\text {efr }}$, but the results for $\chi^{(2)}$ do not confirm this. The very low vilues for 2 and $\mathbf{4}$ are apparently due to poor film quility caused by extreme stiffness of the monolayers at the air-water interface and consequent poor ordering. Addition of a nitro group is seen by comparison of 1 and 3 to increase $\beta_{\text {eff }}$ significantly, but at the cost of increasing the apparent average tilt of the chromophore from the normal. Somewhat surptising is the compurison of effective molecular nonlinearities between 5 and 8 , in which increasing the length of the conjugated system by adding a $-\mathrm{CH}=\mathrm{CH}$ - double bond to the bridge has no apparent effect on $\beta$. "Conventional wisdom" would predict a significant increase in $\beta$ from such a substitution due to the lengthening of the conjugated $\pi$-clectron system.

The effect of end group change in hemicyanines 11-13 is somewhat unclear. In principle one would expect little effect on $\beta$ but the effective value for $\mathbf{1 3}$ is significantly lower, interesting in light of the enhanced SHG from an internal salt hemicyanine on water reported by Loew et al. ${ }^{[18]}$ This effect could well be due to the fact that the hemicyanine 
chromophore appears to have a strong off-axis component of $\beta$ which can render a simplified evaluation of the data suspect. ${ }^{[1 ;-20]}$

The enhancement of 7 relative to 6 appears to be based on the increased planarity of the conjugated system created by interaction between the OH group and the nitrogen in the bridge. [21] As the increase in $\beta$ was achieved without a shift of the absorption closer to the hammonic wavelength this represents an interesting improvement.

The results for the thioethers are particularly interesting; comparing $\gamma^{(2)}$ for 6 with 14 and 9 with 10 we see that a thioether as donor group offers a significant improvement in nonlinearity over an ether group, although the absorption shift for the phenylhydrazone is zero and the shift for the styrylpyridinium is also quite small. The thioether group as donor was reported previously by Leslie and Teng ${ }^{[22]}$ and predicted to be a good donor by $L i$ ct al. ${ }^{[23]}$ Although the amino group appears on the basis of our results and previous titerature still to be the strongest donor group for nonlinear optical effects the thioether moiety seems to offer a desirable combination of relatively high nonlinearity and good filmbuilding and spectral properties. On the basis of these direct comparisons and the earlier reports it would appear to be a promising group for future study.

In summary, variation of substituents in amphiphilic dyes was found to affect the macroscopic nonlinear optical properties both through changes in molecular nonlinearity and effects on the structure within the LB film. Furthermore, the thioether group was identificd as a promising candidate for nonlinear optics applications in LB films. The future applicabjlity of such films depends however not only on high $\chi^{(2)}$ values, bur also on the solution of other problems, such as buildup of stable multilayers, creation of waveguide structures and improvement of optical quality. Other articles in this issue deal with some of these aspects.

Received: June 1, 1990

[1] O. A Aktsipelrov, N. N Akbmediev, F. D, Mishina, V. R. Novak, JET Lett. $37(1983) 207$.

[2] R. C. Hall, G. A. Lindsay, S. T. Kowel, L. M. Hayden, B. L. Andersor, B. G. Higgins. P. Stroeve, M. A. Srinivasan, SPIE 824 (1987) 121.

[3] G. Decher, B. Tieke, C. Bosshard, P. Günter, J. Chem. Soc., Chem. Com mur. 1988. 933 .

[4] I. R. Girling. P. V. Kolinsky, C. M. Montgomery, Electron. Leld. 21 (1985) 169. D. B. Neal, M. C. Petcy. G. G. Roberts, G. G. Ahmad. W. J. Fenst, I. R. Gitling, N. N. Cade, P. V. Kolinsky, I. R. Peterson, Electron. Lett. 22 (1986) 460 .

[5] I. Ledoux, D. Josse, J. Zyss, T. MeLeat, R. A. Habn, P. I. Gordon, S Allen, D. Lupo, W. Prass, U. Schetuenann, A. Laschewsky, H. Ringgoof, (n I. Messier, F. Kaymar, P. Prasad, [). Ulrich, (Eds,): Non/inear Optical Effecte in Organic Pulpmers. Kluwer, Dordrecht 1984.

[6] G. Marowsky, L. F. Chi, D. Möbius, R. Steinhoff, Y. R. Shen, D. Dorsch, B. Rieger, Chem. Phys. Leit 147 (1983) 420.

[7] D. W. Kalind, S. G. Gitubb, Thin Solid Films r60 (1988) 363.

[8] I. Huang, A. Lowis, T. Rasing, If Phys. Chem. 92 (1988) 1756.

[9] R. Popovitz-Biro, K. Hill, E. M. Landau, M. I,ahav, L. Leiserowitz, J Sagiv, H. Hsiung, G. R. Meredith, H. Vanherzeele, J. Am. Chem. Stc , 110 (1988) 2672 .

[10] J. W. Bartor, M. Bahaenko, B. Moyle. N. M. Rateliffc, J. Chemt. Soc. Chem. Commin. 1988.488.
[11] M. Orrit, D. Möbius, U. Lebmann, H. Maier, J. Chem. Phys. 85 (1986) 4966.

[12] P. Guyot-Sionnest, W. Chen, Y R, Shen, Phys. Rev. B. 33 (1986) 8254

[13] V. Mizrahi, J. E. Sipe, J. Opt. Soc. Am. B 5 (1988) 666

[14] J. E. Sipe, J, Opt. Sol, Am. B 4 (1987) 481 .

[15] D. Neher, Doctoral Dissurtation, University of Mainz (1990).

[16] M. Born, E. Wolf: Prinsiples of opties, 6th ed. Perganon Press, Oxtord 1980

[17] D. J. Williams, Angew. Chem. Int. Ed. Engl. 23 (1984) 690; Anguw. Chem. $96[1984) 637$

[18] J. X. Huang, A. Lewis, L. Loew, Biophys, J. 53 (1988) 665

[19f $G$ Gilberg, R. Keosisu, L. Pruksurnukul, D. Lupo, aspublished regults

$[20]$ C. W. Dirk. R. I. Twieg, G. Wagniere, J. Am. Chem. So\&. 108 (1986) 5387

[21] T. Leslic, private conmunication

[22] T. M. Leslie. C. C. Teng, unpublished results.

[23] D. Q. Li, M. A. Ratner, T. J. Marks, J. Am. Chem. Sor. 110 (1988) 1707 